\title{
versants
}

\section{Las traducciones del Quijote}

\author{
Patrizia BotTA ${ }^{\mathrm{I}}$ \\ Università di Roma «La Sapienza"
}

\begin{abstract}
Se ilustra brevemente el debate sobre «Las traducciones del Quijote» a las distintas lenguas de los participantes (de Bélgica, China, Francia, Grecia, Inglaterra, Italia, Japón, Polonia, Rumanía, Rusia).

Keywords: Quijote, Cervantes, traducción, lengua del XvII, hispanismos nacionales.
\end{abstract}

La Fundación Duques de Soria, que organizó el Homenaje al Hispanismo Internacional (Madrid, Real Academia Española y Palacio Real de El Pardo, 26 de septiembre de 2018), nos asignó para la Mesa Redonda número 5 el tema de la Traducción, y a nosotros nos pareció que la muestra más elocuente de lo que es el Hispanismo en tantas naciones distintas (como las que representábamos en nuestra Mesa) era la traducción del Quijote a nuestras propias lenguas nacionales, o sea el tributo que cada Hispanismo quiso rendirle al mayor clásico de la Literatura Española, divulgándolo y promoviendo su recepción entre culturas distintas y hasta lejanas de la original. Si Hispanismo significa la dedicación de un no nativo a la lengua y a la cultura de España, ocuparse de su obra maestra es la cumbre de dicha dedicación, máxime en el caso de la traducción que significa interpretar el Quijote línea por línea en todas sus entrañas.

También nos pareció que la traducción del Quijote representaba un tema transversal o un centro de interés común para los participantes de la Mesa, que éramos de Naciones muy distintas, porque de hecho el Quijote se había traducido en todos nuestros idiomas (sabido es que fue la obra más traducida en el mundo tras la Biblia) y era por lo tanto una vivencia común que cada Nación había tenido hacia España y hacia el Hispanismo, y un tema propicio para el debate.

Desde luego, en nuestra Mesa solo nos ocupamos de las traducciones a las lenguas de los participantes, que cada uno expuso (Lieve Behiels para Bélgica, Dong Yansheng para China, Pierre Civil para Francia, Victor Iva-

I Patrizia Botta (Universidad de Roma "La Sapienza", Italia), Presidenta de mesa. Con la colaboración de Lieve Behiels (Universidad de Lovaina, Bélgica); Pierre Civil (Universidad París 3 Sorbonne Nouvelle, Francia); Kenji Inamoto (Univesidad Doshisha, Japón); Victor Ivanovici (Universidad "Aristóteles" de Salónica, Grecia); Marcin Kurek (Universidad Wroclawski, Polonia); Sorin Mărculescu (Unión de Escritores de Rumanía, Bucarest); Lilia Moiseenko (Universidad Estatal Lingüística de Moscú, Rusia); Dorothy Sherman Severin (Universidad de Liverpool, Reino Unido), Dong Yansheng (Universidad de Estudios Extranjeros de Bejing, China). 
novici para Grecia, Dorothy Severin para Inglaterra, Kenji Inamoto para Japón, Marcin Kurek para Polonia, Sorin Mărculescu para Rumanía, Lilia Moiseenko para Rusia y yo misma para Italia). En algunos casos (Italia y Rumanía), siendo los participantes los propios traductores de la obra, se ilustraron, con ejemplos de primera mano, los escollos de la labor ante un texto antiguo que es a la vez una obra de arte del lenguaje, como dijo Hatzfeld (I949 [I927]), con una lengua cómica que es un constante desafío para el traductor. Igualmente se comentaron las dificultades que los traductores suelen exponer en sus propias Advertencias, sea brevemente sea a través de detallados párrafos.

Se destacó el arco cronológico ininterrumpido de las traducciones del Quijote, desde las primeras, coetáneas del original (inglesas de I6I2-I620, I687, francesas de I6I4, I6I8, I677, italiana de I622-I625 y neerlandesa de I657), hasta nuestros días, cuando asistimos a una eclosión de traducciones que se promovieron para el IV Centenario de la obra (2005 y 20I5) o de la muerte de Cervantes (2016).

Las versiones en lengua francesa a lo largo de la historia tuvieron mucha difusión en toda Europa y a menudo sirvieron de base a traducciones en otras lenguas (griego, inglés, neerlandés, polaco, rumano, ruso), e igual ocurrió con la italiana de I622-I625 que se usó de modelo en algún caso (griego), o con una de las inglesas (para el japonés), si bien la gran mayoría de las veces se tradujo directamente a partir del original español.

Se aludió a la cercanía o lejanía del español de los idiomas a los que se traduce, desde las lenguas románicas hermanas de la española (francés, italiano, rumano) o culturalmente próximas (griego) hasta las que proceden de cepas distintas, ya sea europeas (inglés, neerlandés, polaco, ruso), ya sea orientales (chino, japonés), que lógicamente tienen mayores dificultades al traducir por ser portadoras de idiosincrasias distintas y por su misma distancia geográfica, cultural y lingüística de España.

Se comentaron sobre todo las traducciones completas de la obra, pero también se mencionaron algunas de las parciales (como las sueltas del $\mathrm{Cu}$ rioso Impertinente) o las adaptaciones para niños, o, al margen, las versiones teatrales.

También se destacaron las principales modalidades de la traducción, desde las rigurosamente fieles y filológicas hasta las que se tomaron mayores libertades con respecto al original (con cortes, añadidos, etc.), sin que faltaran los comentarios de varios tipos de error que se generan cuando se traduce, por ejemplo, del español al chino, o al polaco, lo que, en opinión de severos reseñadores como Sabik, demuestra que el Quijote es intraducible y solo nos queda «la lectura gozosa del original» (I998: I34 apud Kurek, 2019), a la zaga de lo que decía Cervantes de la traducción en su conocido pasaje sobre los tapices flamencos (DQ, II.62). 
Otro tema fue el de la identidad o perfil de los traductores a lo largo de la historia, desde los profesionales hasta los literatos y los catedráticos más recientes que reflejan la mayor boga del estudio del español en la Universidad. Se ha destacado que las traducciones del Quijote a veces corren parejas con la formación de los Hispanismos nacionales.

En definitiva, el conjunto de las traducciones comentadas nos da el pulso de lo que fue la recepción y la divulgación del Quijote en las distintas culturas nacionales, que fueron determinantes a la hora de la formación de su mito universal.

A continuación, el resumen de cada intervención:

Bélgica (Lieve Behiels): Las traducciones del Quijote al neerlandés son cinco. La primera corresponde a la época barroca, la segunda refleja la mentalidad de la Ilustración, la tercera se enmarca en la tradición romántica e idealizante de la obra, la cuarta refleja el estado de la investigación filológica hasta los años cuarenta del siglo xx. La traductora de la última versión, Barber van de Pol (1997), reivindica su visibilidad. Estas traducciones no solo nos informan sobre cuatro siglos de interpretación de la novela sino que además son ilustrativas de las concepciones cambiantes acerca de la traducción literaria.

China (Dong Yansheng): Al traducir el Quijote al chino, el traductor tiene por lo menos dos barreras que salvar: la cultural y la lingüística. En la primera están incluidos los problemas derivados de diferentes hábitos cognitivos determinados por las respectivas formas de segmentar el mundo, respectivas tendencias asociativas, respectivas preferencias de observar el entorno y respectivos derroteros históricos con imborrables sedimentos costumbristas, religiosos, mitológicos. En la segunda, cabe destacar especialmente problemas de selección semántica, correcta captación de las estructuras gramaticales, registro del lenguaje, correspondencia estilística, traslado de discursos repetidos, así como juego de palabras. Se comentan 2 versiones de otros traductores (I. 堂吉诃德, traductora Yang Jiang, I99I. 2. 唐 吉诃德, traductor Liu Jingsheng, 1995).

Francia (Pierre Civil): La primeras traducciones francesas del Quijote fueron tempranas (Oudin I6I4 y Rosset I6I8) y constituyeron puntos de partida de unas trece versiones a lo largo de más de cuatro siglos. La recepción del Quijote de I605 y las circunstancias de la primera versión francesa revelan la importancia de los contextos culturales y políticos entre los dos países. El Quijote se impone en pocos años como clásico y se convierte en una inagotable fuente de inspiración de creaciones francesas literarias y plásticas. Las declaraciones de intenciones que encabezan las traducciones de Schulman, Canavaggio y Fanlo dan buena idea de lecturas e interpretaciones siempre renovadas de la obra maestra cervantina. 
Grecia (Victor Ivanovici): Procedente de una entrada de enciclopedia, este informe sigue los avatares de las quince traducciones cervantinas (sobre todo las quijotescas) al griego moderno, desde las primeras versiones, manuscritas, del siglo XVIII, hasta las recientes ediciones con motivo de los aniversarios de Cervantes y sus obras, a lo largo de la segunda década del siglo XXI.

Inglaterra (Dorothy Severin): El tema de las veinte traducciones del Quijote al inglés es tan popular que hay un sitio web dedicado al asunto. Sin embargo, vale la pena echar una ojeada sobre la historia de las traducciones para evaluar su importancia y calidad. También se da una nueva noticia de la primera aparición en I607, en el teatro inglés, del plot del Quijote, es decir el de la imitación de los libros de caballerías por un hombre de la burguesía.

Italia (Patrizia Botta): Son diecisiete las traducciones italianas completas de la obra, desde las primitivas (I622) hasta las últimas (2015) promovidas para los Centenarios, todas basadas en el original español. Se comentan las dificultades de la lengua del Quijote que son otros tantos escollos en la traducción (hablas cultas y campesinas, arcaísmos, bisemias, neologismos, lenguas de especialidad, lengua cómica, nombres parlantes, prosímetro, refranes, retórica, sintaxis difícil, etc.) y se dan algunos ejemplos de solución.

Japón (Kenji Inamoto): La traducción del Quijote al japonés empezó a realizarse después de la Revolución de Meiji (I868) a finales del siglo XIX. Al principio, a través de la versión inglesa, luego directamente del español al japonés, aparecieron once traducciones de la Primera y siete de la Segunda Parte del Quijote, aunque salieron a la luz muchas adaptaciones y versiones infantiles. Ya en la segunda mitad del siglo xx teníamos dos traducciones fiables de Hirosada Nagata y de Yû Aida pero recientemente aparecieron cuatro nuevas traducciones.

Polonia (Marcin Kurek): La historia del Quijote en Polonia refleja los avatares que ha vivido la literatura española en este país: una llegada tardía y a menudo a través de la lengua francesa. De las cinco traducciones existentes hasta la fecha, las dos primeras se realizaron a partir de la versión de Filleau de Saint-Martin, llegando la obra de Cervantes casi dos siglos después del original, mientras que la primera traducción del español proviene de los años treinta del siglo Xx. Las traducciones polacas que hay son las de Franciszek Podoski (1786), Walenty Zakrzewski (1855), Edward Boyé (1932), Anna y Zygmunt Czerny (1955), Wojciech Charchalis (2016).

Rumanía (Sorin Mărculescu): Se comentan las seis traducciones al rumano, parciales y completas del Quijote. La más reciente (2004, ed. revisada 2009), integral y hecha por un solo traductor, se debe al autor de la ponencia. El traductor pasa en revista los criterios de su versión: literalidad expresiva, musicalidad, modernidad léxica, traducción y no equivalencias de los proverbios, equivalencias cómicas de los nombres propios, rehuso de todo 
parangón literario rumano anterior, etc. El Quijote es vivido por su último traductor rumano como una experiencia total, no solo literaria o filológica: él le considera a la vez como un ars vivendi y un ars moriendi.

Rusia (Lilia Moiseenko): Se describen las ocho traducciones más famosas del Quijote al idioma ruso. Las primeras partieron de textos distintos al original español, fundamentalmente de traducciones francesas. Asimismo, se explica la importancia de una buena traducción en la suerte que un libro y sus personajes puedan correr a la hora de llegar a una nueva cultura: los traductores al ruso fueron capaces de leer creativamente el Quijote, tanto que este héroe encontró en Rusia su segunda patria. El famoso hidalgo se convirtió en un nombre, para la cultura rusa, capaz de proyectar una imagen diferente a la que tiene en la cultura nativa española, e incluso a aquella que presenta en otras culturas receptoras.

\section{Bibliografía citada}

Hatzfeld, Helmut, «El Quijote» como obra de arte del lenguaje, Madrid, Aguirre, I949 [1927].

Kazimierz, Sabik, Entre misticismo y realismo. Estudios sobre la recepción de la literatura española en Polonia, Universidad de Varsovia, 1998.

Kurek, Marcin, «Las traducciones del Quijote al polaco» (2019, en prensa). 
